\title{
Microfabrication of Ceramics by Co-extrusion
}

\author{
Charles Van Hoy, Andrew Barda, Michelle Griffith, ${ }^{\star \dagger}$ and John W. Halloran* \\ Department of Materials Science and Engineering, University of Michigan, Ann Arbor, Michigan 48109-2136
}

Fine-scale ceramic objects are fabricated by forcing a thermoplastic ceramic extrusion compound through a die with reduction ratio $R$. Objects with complex shapes are fabricated by assembling an extrusion feedrod from a shaped ceramic compound with space-filling fugitive compound. After each reduction state, $R^{2}$ extrudates are assembled into a feedrod and extruded again, reducing the size and multiplying the number of shaped objects. Several stages of extrusion produce arrays of objects in the size range of $10 \mu \mathrm{m}$.

\section{Introduction}

$\mathrm{F}$ INE-SCALE ceramic objects can be produced as free-standing three-dimensional objects in the millimeter size range using conventional pressing or molding techniques, but it is impractical to use these methods for much finer objects. Tape casting is convenient for planar objects as thin as about $10 \mu \mathrm{m}$, but the features are small only in one dimension. Fine-scale structures have been produced by a variety of techniques for piezoelectric composites, ${ }^{1}$ which feature arrays of small simple objects. More complicated fine-scale shapes are envisioned for certain advanced actuators, ${ }^{2}$ for which a process with more freedom of shape is desirable. We report here on ceramic microfabrication by co-extrusion (MFCX), a new method to produce axisymmetric ceramic objects with micrometer-size features in two dimensions.

The reduction in area that occurs during extrusion can be used to create objects which are microscopically small in two dimensions. Subsequent slicing of the extrudate could subdivide them into small three-dimensional objects. The coextrusion process that we report here for microfabrication, however, is not conventional ceramic extrusion. In conventional extrusion, the fabricated object takes the cross-sectional shape of the extrusion die and can be no smaller than the die orifice. A complex extrusion die is needed to form a complex shape. The MFCX process uses a simple round or square die for size reduction. Shaping is done by using a shaped object of two or more materials as the extrudate. One material is the primary material, the ceramic which is to be microfabricated. The second material is a fugitive substance, whose function is to fill space and have similar flow behavior as the primary material during extrusion. These are extruded together, or coextruded, to reduce the cross-sectional dimensions. This paper presents the method of microfabrication by co-extrusion, with examples of several shapes in alumina and $\mathrm{PbO}$-containing ferroic ceramics.

\section{Co-extrusion}

The microfabrication process is illustrated in Fig. 1. This illustrates an alumina-containing plastic extrusion body,

A. Safari-contributing editor

Manuscript No. 191648. Received July 26, 1996; approved May 23, 1997. Supported by the Defense Advanced Research Projects Agency under the Office of Naval Research Grant No. N00014-93-0302.

"Member, American Ceramic Society.

Now at Sandia National Laboratory, Albuquerque, NM. molded into the shape of a 10-mm tall " $\mathrm{M}$ '. Appropriatelyshaped sections of a carbon-black-containing extrusion body are combined with the plastic alumina " $M$ " to make a solid rectangular prism. This prism is a feedrod for a square piston extrusion die. Consider the extrusion of a 10-mm-long feedrod. A first-stage extrusion through a 5:1 die creates an undistorted 2-mm-high alumina/carbon black " $\mathrm{M}$ ', which is $250 \mathrm{~mm}$ long.

The first-stage extrudate is cut into 25 pieces, $10 \mathrm{~mm}$ long, which are reassembled into a $10-\mathrm{mm}$-high feedrod. This second-stage feedrod has 25 objects $/ \mathrm{cm}^{2}$. A second-stage extrusion with a 5:1 reduction ratio again creates a 2-mm-high prism, $250 \mathrm{~mm}$ long, but with a cross section consisting of 25 " $M$ '' shapes, each $400 \mu \mathrm{m}$ tall. Reassembling again creates a feedrod with 625 objects $/ \mathrm{cm}^{2}$. A third-stage extrusion reduces the size of the objects to $80 \mu \mathrm{m}$ and increases the population to $15625 / \mathrm{cm}^{2}$. A fourth stage produces 390625 objects $/ \mathrm{cm}^{2}$, each $16 \mu \mathrm{m}$ high.

A large population of microscopic objects quickly builds up with repeated co-extrusion, even though at each stage one handles conveniently-sized objects in relatively small numbers. If an object of size $S_{0}$ is subjected to a sequence of $N$ reduction stages, each with reduction ratio $R_{i}$, the final size $S_{N}$ becomes

$$
S_{N}=S_{0}\left[\prod_{i-1}^{N} R_{i}\right]^{-1}
$$

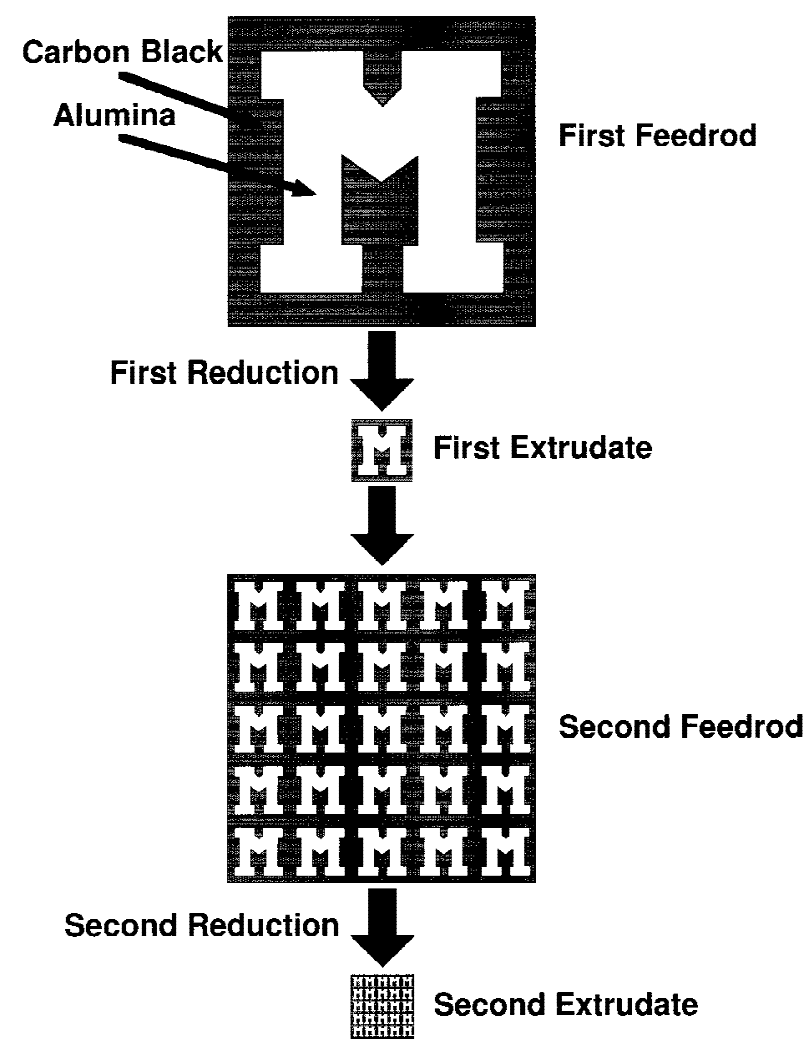

Fig. 1. Process schematic for microfabrication by co-extrusion. 
For the case where the reduction ratio is the same for all stages, this is simply

$$
S_{N}=\frac{S_{0}}{R^{N}}
$$

so the size is decreased by a power law of the reduction ratio raised to the number of stages. The population of objects, expressed as the number per unit cross-sectional area after $N$ reduction stages, $P_{N}$, is

$$
P_{N}=P_{0}\left[\prod_{i-1}^{N} R_{i}\right]^{2}
$$

or if the reduction ratio is constant

$$
P_{N}=P_{0} R^{2 N}
$$

While the microfabricated objects become tiny and very numerous, at each stage the extrudate itself is never smaller than $S_{0} / R$, several millimeters in size. When extrudate is cut and rebundled, one handles $R^{2}$ pieces, which typically number about 25-36. After the last stage of reduction, the microscopic objects are arrayed within the extrudate in a convenient form for sintering.

The fugitive material can be any substance that extrudes well and has flow properties which can be matched with the primary material, provided it can be cleanly removed after microfabrication. This includes materials which can be dissolved away, evaporated, or removed by reaction. Carbon black is a very convenient fugitive substance for materials which are sintered in air. It is inexpensive and typically formulated to enhance dispersion in polymers. During slow heating in air, carbon black does not appreciably oxidize until about $500^{\circ} \mathrm{C}$, which is above the temperature required for binder removal. Thus polymer removal and fugitive removal are conveniently separated. Under appropriate conditions, carbon black oxidation is gradual, so it need not disrupt microfabricated articles. It works well for stable oxides like alumina. More care must be taken for readily reduced ceramics, such as lead zirconate titanate $(\mathrm{PZT})^{3}$, but it is possible to remove the carbon black with no apparent damage to the ceramic.

\section{Experimental Procedure}

The MFCX method is similar to what we have previously reported for producing textured ceramics. ${ }^{4} \mathrm{~A}$ thermoplastic extrudable mixture is made by compounding ceramic powder in a heated shear mixer. ${ }^{*}$ Ethylene vinyl acetate $(\mathrm{EVA})^{\S}$ is melted at $140^{\circ} \mathrm{C}$ in a $60 \mathrm{~mL}$ mixer-measuring head equipped with roller blades. Ceramic powder is gradually added, with small additions of methoxypolyethylene glycol $^{\mathrm{TI}}$ as a plasticizer, to yield a final composition which is 50 vol\% ceramic. The compound is brought to a specific viscosity level around $18 \mathrm{~m} \cdot \mathrm{N}$ of torque at $60 \mathrm{rpm}$, by adjusting the polymer/plasticizer ratio. The flow field in the torque rheometer is complex, but can be approximately related to viscosity and shear rate. ${ }^{5}$ With our particular roller mixer geometry, $60 \mathrm{rpm}$ corresponds to a maximum shear rate at the wall of $150 \mathrm{~s}^{-1}$, and $18 \mathrm{~m} \cdot \mathrm{N}$ of torque implies an apparent viscosity of $3480 \mathrm{~Pa} \cdot s$. The ceramic powders include an alumina, ${ }^{\dagger \dagger}$ a lead zirconate titanate (PZT), ${ }^{*}$ and a lead magnesium niobate-lead titanate (PMNPT). ${ }^{\S}$ The particle size of these powders is about $0.5 \mu \mathrm{m}$. A

Plasti-Corder PL 2100 Electronic Torque Rheometer, C. W. Brabender, South Hackensack, NJ.

${ }^{\S}$ ELVAX 470, E. I. DuPont Co., Wilmington, DE.

"Carbowax MPEG 550, Union Carbide Corp., Danbury, CT.

${ }^{\dagger}$ Reynolds RC-HP-DBM, Reynolds Metal Co., Bauxite, AK

EC-76, EDO Western, Salt Lake City, UT

\$AVX Ceramics Corp., Myrtle Beach, SC. carbon black powder, ${ }^{\text {III }}$ with median particle size of $70 \mathrm{~nm}$, was used as the fugitive material. The compound was mixed twice to improve homogeneity.

The primary and fugitive compounds are compression molded into suitable shapes using steel tooling at about $150^{\circ} \mathrm{C}$, and assembled into a feedrod. A laboratory-scale piston-style extruder, ${ }^{\dagger \dagger \dagger}$ with either a $22 \mathrm{~mm}$ diameter cylindrical or a 25.4 $\mathrm{mm}$ square barrel, presses the feedrod through a $60^{\circ}$ cone in the heated extrusion die. Extrusion is typically conducted at $105^{\circ} \mathrm{C}$ at a piston speed of $6 \mathrm{~mm} / \mathrm{min}$, with ram pressures around 1 $\mathrm{MPa}$. The extrudate is larger than the die orifice by about 3-8 linear percent, due to die swell. This causes a slight distortion of the square extrudate so that it has a slightly barrel-shaped cross section. The extrudate is collected after the first extrusion pass, cut into suitable lengths, and reassembled into a feedrod. This is consolidated at $150^{\circ} \mathrm{C}$ by pressing at $2 \mathrm{~mm} / \mathrm{min}$ to 1 $\mathrm{MPa}$. The reassembled feedrod is extruded a second time, and the process is repeated for up to four stages.

The microfabricated objects are buried in powder for support during sintering and to slow oxygen transport to the carbonaceous fugitive materials, and thereby avoid thermal runaway during the exothermic oxidation. The PZT and PMN-PT are buried in a PZT packing powder before. The EVA binder is removed with the following heating schedule in air: $5^{\circ} \mathrm{C} / \mathrm{min}$ to $100^{\circ} \mathrm{C} ; 1^{\circ} \mathrm{C} / \mathrm{min}$ to $250^{\circ} \mathrm{C}$; hold $1 \mathrm{~h}$; heat $1^{\circ} \mathrm{C} / \mathrm{min}$ to $500^{\circ} \mathrm{C}$; hold $1 \mathrm{~h}$. Carbon black removal and sintering are done by heating at $5^{\circ} \mathrm{C} / \mathrm{min}$ to $1600^{\circ} \mathrm{C}$ (for alumina), $1250^{\circ} \mathrm{C}$ (for PZT), or $1100^{\circ} \mathrm{C}$ (for PMN-PT).

\section{Results}

\section{(1) Alumina "M"' Shapes}

A series of microscopic " $M$ " shapes were fabricated from alumina by MFCX. A $25.4 \mathrm{~mm}$ high, $50.8 \mathrm{~mm}$ long ' $\mathrm{M}$ ' was fashioned out of the alumina/EVA compound by carving sections of it by hand with a scalpel. The carbon black/EVA compound was similarly carved to fill out the spaces in the square cross section. These were pressed into a $25.4 \mathrm{~mm}$ square feedrod, and extruded through a $4 \mathrm{~mm}$ square orifice. After accounting for die swell, the actual reduction ratio was $R=$ 5.5. Figure 2(A) shows the $4.8 \mathrm{~mm}$ high ' $\mathrm{M}$ '" in the green state after the first reduction stage. The first-stage extrudate was surrounded by $10 \mathrm{~mm}$ thick slabs of the carbon black compound and extruded for a second stage. Figure 2(B) shows an $840 \mu \mathrm{m}$ tall " $\mathrm{M}$ ' after two reduction passes. A third stage feedrod was made by assembling 25 sections and reduced in a third stage to produce an array of 25 " M's, each about 150 $\mu \mathrm{m}$ high, shown in Fig. 2(C). A fourth stage of assembling and reduction produced an array of 625 ' $M$ 's, each about $27 \mu \mathrm{m}$ high. These four stages of reduction at $R=5.5$ had reduced the size of the objects by a factor of 915 times, without significant distortion of the shape.

The extrudate was sliced into $2 \mathrm{~mm}$ thick sections before sintering. Figure $3(\mathrm{~A})$ shows four of the objects after the $500^{\circ} \mathrm{C}$ binder removal treatment. Much of the carbon black fugitive material remains, although the carbon immediately adjacent to the alumina has been removed. Sintering at $1600^{\circ} \mathrm{C}$ produces a dense sintered ' $\mathrm{M}$ ', about $18 \mu \mathrm{m}$ high, shown in Fig. 3(B). This object has been overfired, so excessive grain growth limits the resolution of the shape. The sintered objects were about 2 $\mathrm{mm}$ long by $18 \mu \mathrm{m}$ high, looking rather like white whiskers in the optical microscope.

\section{(2) PZT Array}

A PZT-thermoplastic compound was prepared at 50 vol\% ceramic loading as described above. The PZT-plastic com-

\footnotetext{
शाIICabot Black Pearls BP 120, Cabot Corp., Boston, MA.

†Badford Small Scale Extrusion Unit, Bradford University Research, Ltd., West Yorkshire, U.K.
} 


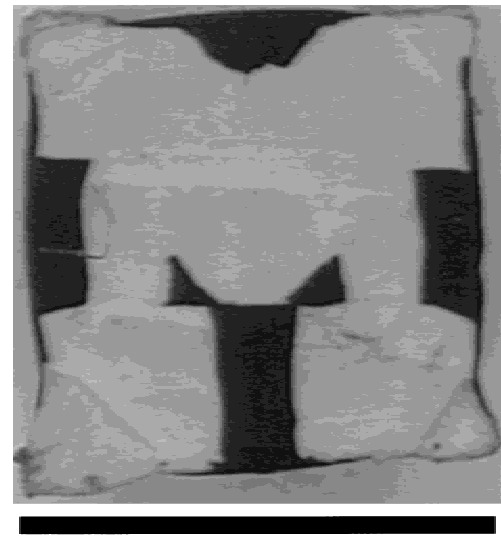

$4.8 \mathrm{~mm}$

(A)

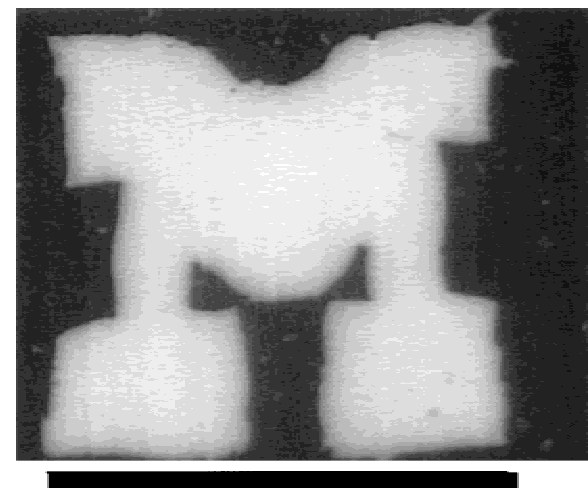

860 microns

(B)

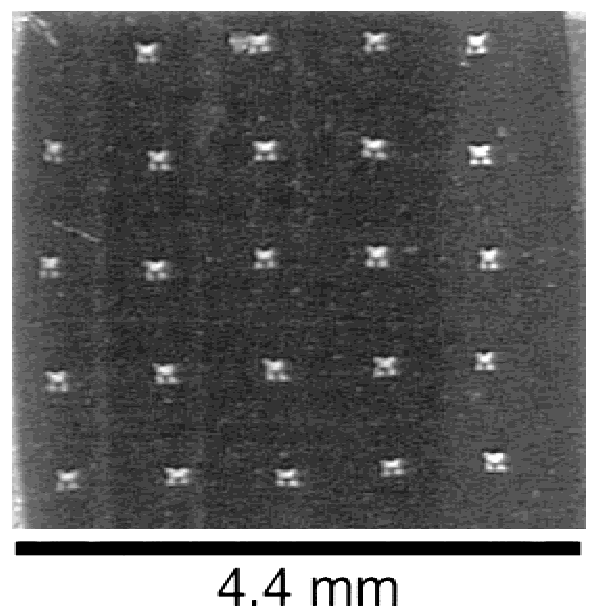

(C)

Fig. 2. (A) $4.8 \mathrm{~mm}$ tall " $\mathrm{M}$ '" in the green state after the first reduction stage. (B) $840 \mu \mathrm{m}$ tall ' $\mathrm{M}$ ' ' in the green state after two reduction passes. (C) An array of 25 'M's, each about $150 \mu \mathrm{m}$ tall.

pound was formed into sheets $0.3 \mathrm{~mm}$ thick by pressing between steel plates at $150^{\circ} \mathrm{C}$. The carbon black-plastic compound was similarly pressed into $0.22 \mathrm{~mm}$ thick sheets. These were cut into squares and stacked alternately. The stack was wrapped with PZT compound to form the first-stage feedrod. This was extruded through a square orifice at a reduction ratio of $R=5.5$. Figure 4 illustrates the reduction process. This is

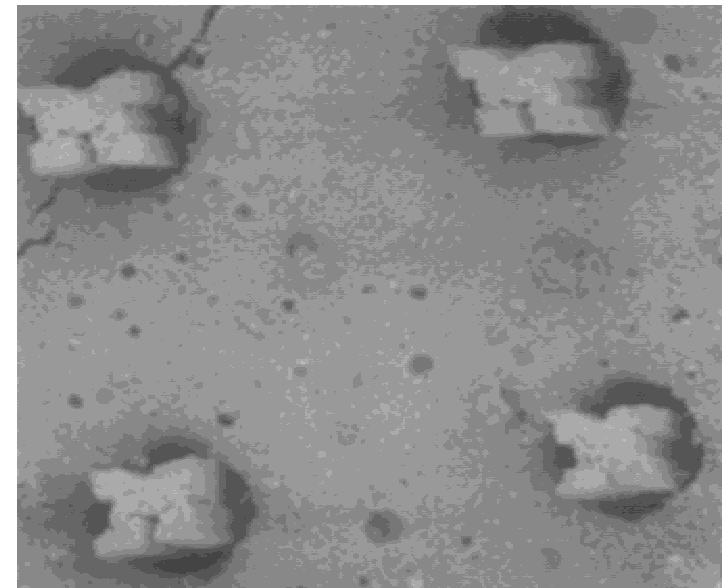

\section{5 microns}

(A)

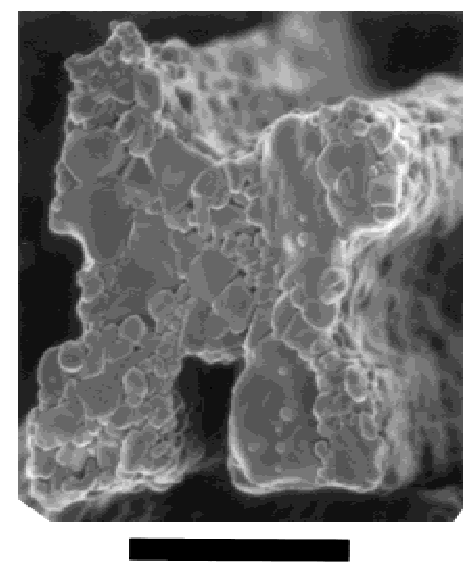

10 microns

(B)

Fig. 3. (A) Four of the third stage reduced "M"s after the $500^{\circ} \mathrm{C}$ binder removal treatment. (B) Dense sintered "M", about $18 \mu \mathrm{m}$ high.

a cross section cut through the cone area of the extrusion rod, showing the PZT-carbon black laminate being reduced in size. The resultant extrudate had a $4 \mathrm{~mm}$ wide array of green $50 \mu \mathrm{m}$ thick PZT lines, each separated by $36 \mu \mathrm{m}$ thick carbon black spacers, as shown in Fig. 5(A). After binder removal, carbon oxidation, and sintering at $1250^{\circ} \mathrm{C}$, we obtained a free-standing array of dense PZT ceramic sheets, which appear in cross section as lines, $40 \mu \mathrm{m}$ wide with $25-30 \mu \mathrm{m}$ spacing. The spacing varies because, after removing the carbon, the PZT lines are unsupported during sintering, and tend to slump.

A finer structure can be produced with a second stage of reduction with $R=5.5$, to yield a green array with green PZT lines about $7 \mu \mathrm{m}$ thick. The array had regions of good order, but also regions where the lines were distorted. These local defects may be associated with inhomogeneities in the plastic compound on the scale of a few micrometers. After sintering at $1250^{\circ} \mathrm{C}$, the array was mounted and polished, and etched to reveal the grain boundaries. Figure 6(A) shows a well-ordered region of the array with sheets about $7 \mu \mathrm{m}$ wide. In many places the line is only one grain thick, as these sintering conditions have produced a PZT grain size comparable to the feature width. A distorted region is shown in Fig. 6(B), where adjacent PZT lines have come into contact with one another.

Fine lines could also be obtained from a single pass reduc- 


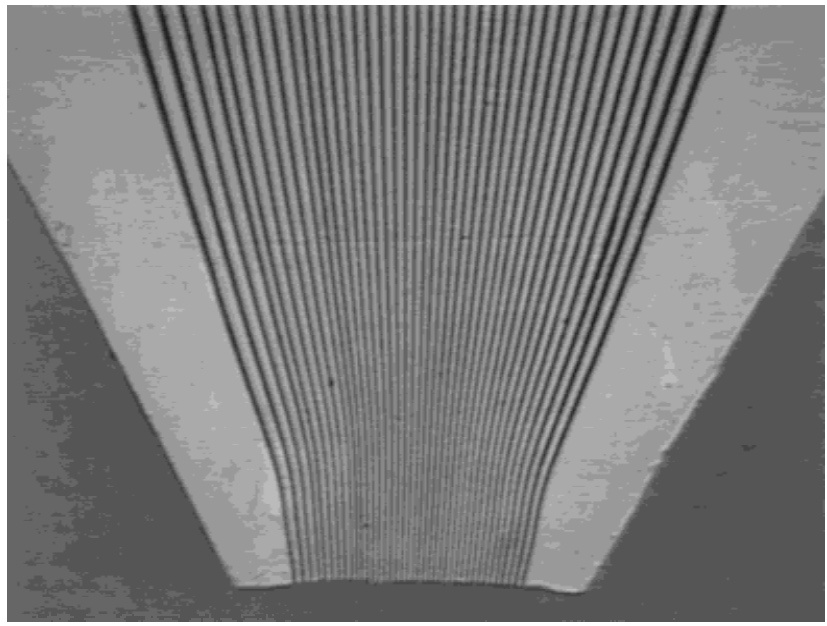

Fig. 4. Cross section of the PZT-carbon black laminate being reduced in the cone section of the extrusion die.

tion with a larger reduction ratio. Figure 7 shows two green PZT-carbon black arrays after a single pass reduction through a round die. The square laminate was placed at the center of the round feedrod, where it occupied about half of the feedrod. The remaining volume was filled by carbon black. Although it was a square feature passing through a round hole, the array suffered little radial distortion. At $R=10: 1$ the array featured 25 $\mu \mathrm{m}$ PZT lines with $20 \mu \mathrm{m}$ carbon black spacers. A more aggressive 20:1 reduction produced $15 \mu \mathrm{m}$ PZT lines with $10 \mu \mathrm{m}$ carbon black spacers. These underwent binder removal and carbon black burnout to produce an undistorted bisque-fired structure. Slumping occurred during sintering at $1250^{\circ} \mathrm{C}$, however, producing the distorted sintered array shown in Fig. 8. The distortion was caused by warping during sintering shrinkage, which in this case occurs for an unsupported array of thin sheets. A suitable support structure would have to be designed to maintain the geometry during densification.

\section{(3) C-Shapes}

A series of "C-Block" actuators ${ }^{2}$ requires a linear combination of bimorphs bent in a $\mathrm{C}$-shape. As a prototype for this, we fabricated the " $C$ '" shape from PZT and PMN-PT. A steel tool with four convex and concave undulations with a peakto-valley amplitude of $6 \mathrm{~mm}$ was used to fabricate green corrugated shapes, $0.3 \mathrm{~mm}$ thick, $25.4 \mathrm{~mm}$ wide, and $50.8 \mathrm{~mm}$ long, from both the PZT-plastic compound and the carbon black-plastic compound. A three layer stack of PZT/carbon black/PZT was built, and assembled with correspondingly shaped solid carbon black-plastic compound to create a feedrod. Figure 9 shows a C-shape with one stage of reduction, after being sliced about $0.5 \mathrm{~mm}$ thick and sintered. The object consists of two parallel undulating walls, each about $50 \mu \mathrm{m}$ thick, separated by a uniform $50 \mu \mathrm{m}$ wide gap created by the central carbon black layer. The peak-to-valley amplitude of the undulations is about $1090 \mu \mathrm{m}$. The PZT appears to have sintered to high density. Figure 10 shows the edge of another $\mathrm{C}$-shape fabricated out of PMN-PT, with one reduction pass, after sintering at $1100^{\circ} \mathrm{C}$ for $1 \mathrm{~h}$. It appears to be fully dense, with a grain size around $2 \mu \mathrm{m}$. The X-ray diffraction pattern of the PMN-PT after extrusion, carbon removal, and sintering, is identical to the starting powder.

\section{(4) Interface Instabilities}

For the alumina/EVA and PZT/EVA systems shown above, the interface between the primary material and the carbon black/EVA fugitive material remains planar throughout the extensive flow that occurs during co-extrusion. This is necessary for microfabrication. Figure 11 is an example of an unstable interface developed between PZT/EVA and a fugitive material

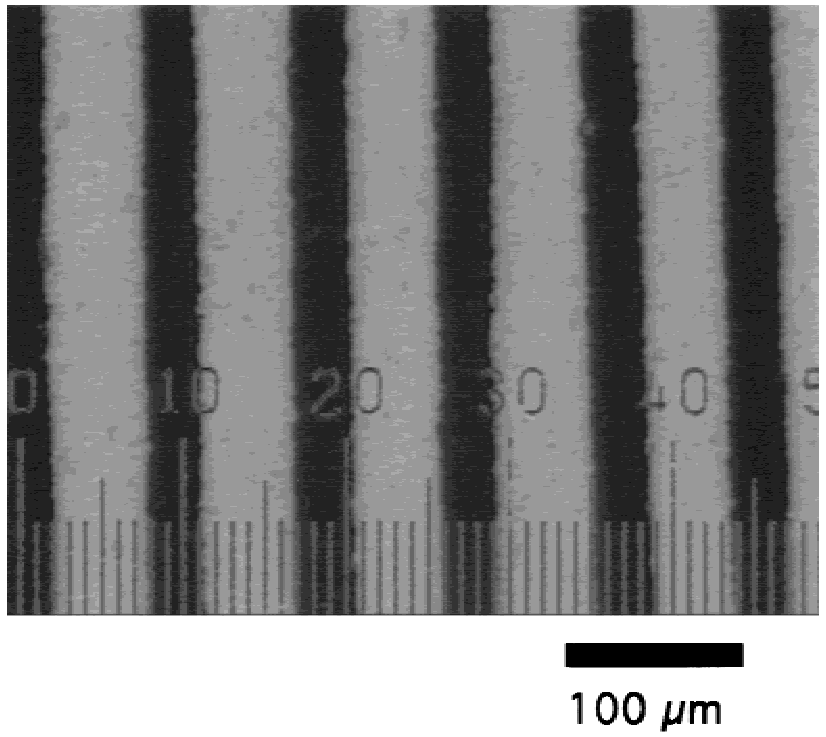

(A)

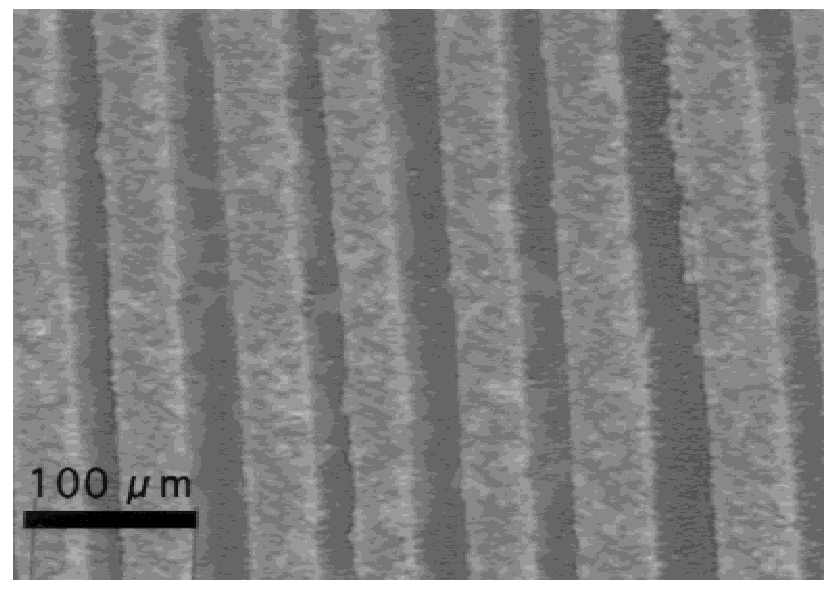

(B)

Fig. 5. (A) Green array of PZT and carbon black after one stage of reduction. (B) Sintered array of PZT lines after one stage of reduction with $R=6$

made from $3 \mu \mathrm{m}$ synthetic graphite powder ${ }^{+*}$ in EVA after an 8:1 reduction. Jagged instabilities with an amplitude around $100 \mu \mathrm{m}$ have developed at the interface. Further instability during a second stage of reduction entirely disrupted the features, creating a random assembly of PZT and graphite regions. Interfacial instabilities can also occur if the thermoplastic carrier polymers are changed. For example, similar jagged instabilities, under certain conditions of temperature and composition, occur with mixtures of EVA and ethylene ethylacrylate (EEA), or with incompatible plasticizers.

\section{Discussion}

Co-extrusion has been conducted successfully over a narrow range of relative viscosities of the two plastic bodies, expressed as a viscosity ratio of the primary compound and the fugitive compound. Satisfactory co-extrusion could be achieved with viscosity ratios ranging from 0.74 to 1.27 . Outside of this range, distortions can be severe. The lower-viscosity melt has 


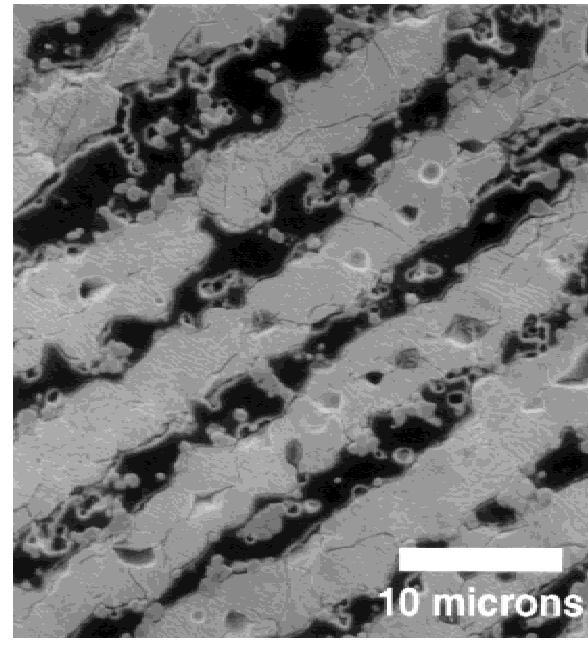

(A)

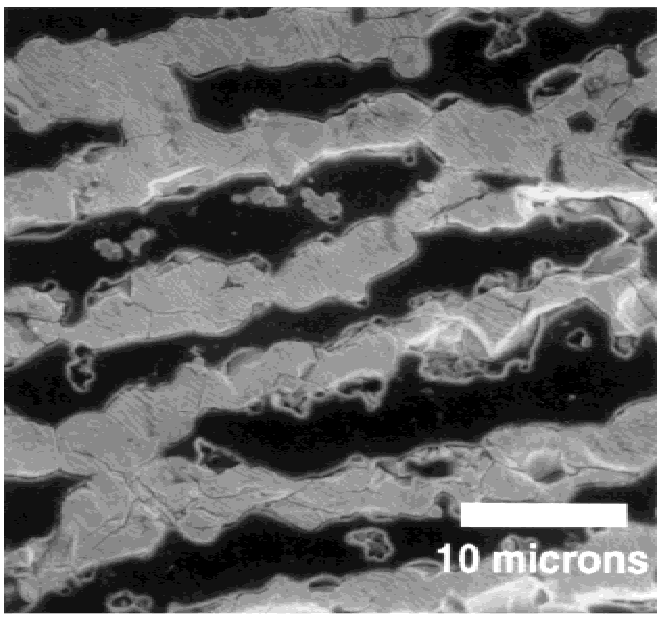

(B)

Fig. 6. (A) Sintered array of PZT lines after two stages of reduction, in a region of good order. Polished and etched. The dark material is the mounting medium. (B) Sintered array of PZT lines after two stages of reduction, in a distorted region, illustrating defects in the PZT lines. Polished and etched. The dark material is the mounting medium.

a tendency to flow around and encapsulate the higher-viscosity melt. It is preferred to have the lower-viscosity material in contact with the die wall. For square tooling, using carbon black as the fugitive and alumina or PZT as the primary, the best results were obtained when the primary material had a 10-20\% higher apparent viscosity.

Shape fidelity of the MFCX process is limited by distortions of the flow field, which depends upon the rheological match between the primary materials and the fugitive material, and by friction and die swell. Under appropriate conditions, reductions of up to $R=20$ can be accomplished in a single pass with little distortion. Up to four consecutive passes have been done with $R=5.5$. It appears that the finest feature that can be fabricated is ultimately limited by the granularity of the extrusion body itself, which is proportional to the largest particles in the powders. The present scale is, however, somewhat larger than this, and distortions can appear at a scale of about $10 \mu \mathrm{m}$. These may be due to undispersed powder agglomerates or heterogeneities of the powder-polymer compound. Inhomogeneities on this scale could have been responsible for the distortions of the 7 $\mu \mathrm{m}$ lines seen in Fig. 6(B).

Interfacial instabilities such as those shown in Fig. 11 disrupt

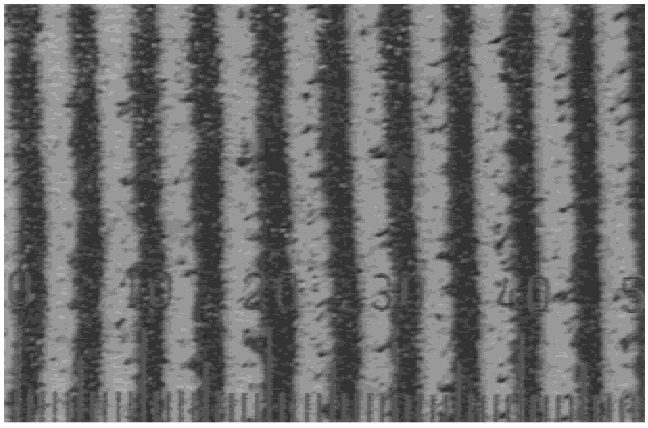

$100 \mu \mathrm{m}$

(A)

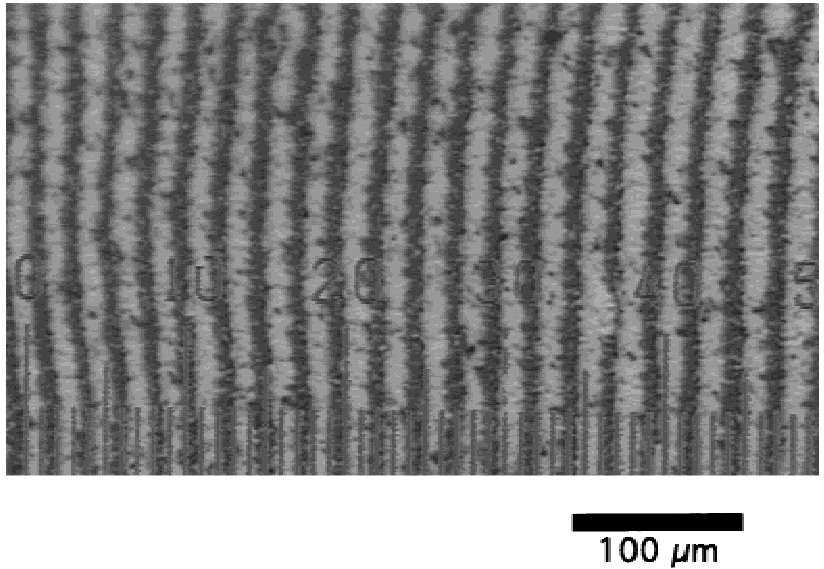

(B)

Fig. 7. Green PZT-carbon black arrays after a single pass reduction through a round die at reductions of 10:1 (A), producing $25 \mu \mathrm{m}$ PZT lines with $20 \mu \mathrm{m}$ carbon black spacers, and 20:1 (B), producing $15 \mu \mathrm{m}$ PZT lines with $10 \mu \mathrm{m}$ carbon black spacers.

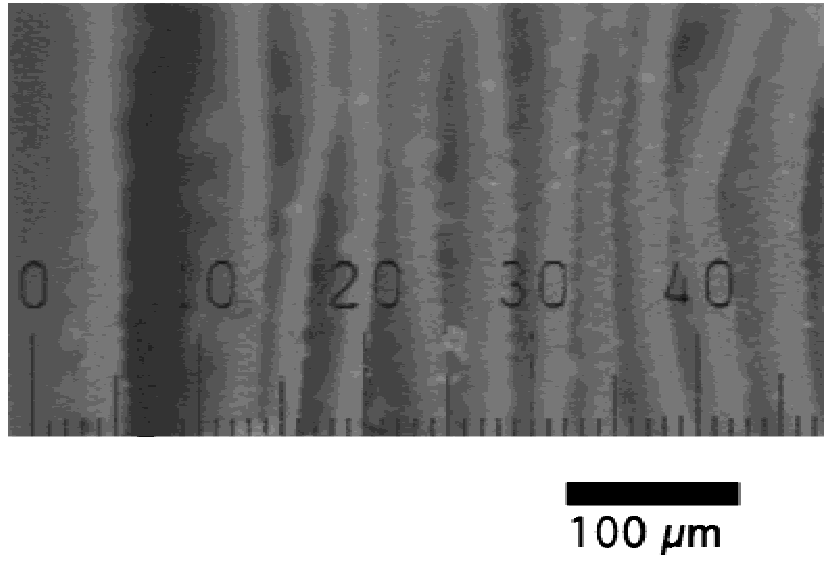

Fig. 8. Sintered PZT array, after 10:1 reduction, showing slumping of unsupported PZT lines.

microfabrication and destroy fidelity. When these occur, they can be ameliorated by improving the viscosity match between the primary and fugitive materials. According to the literature on polymer co-extrusion, ${ }^{6,7}$ under extrusion conditions, it is also necessary to have good adhesion between the two materials being extruded. Adhesion may explain why interfacial instabilities are observed with some combinations of thermoplastic polymers and plasticizers. 


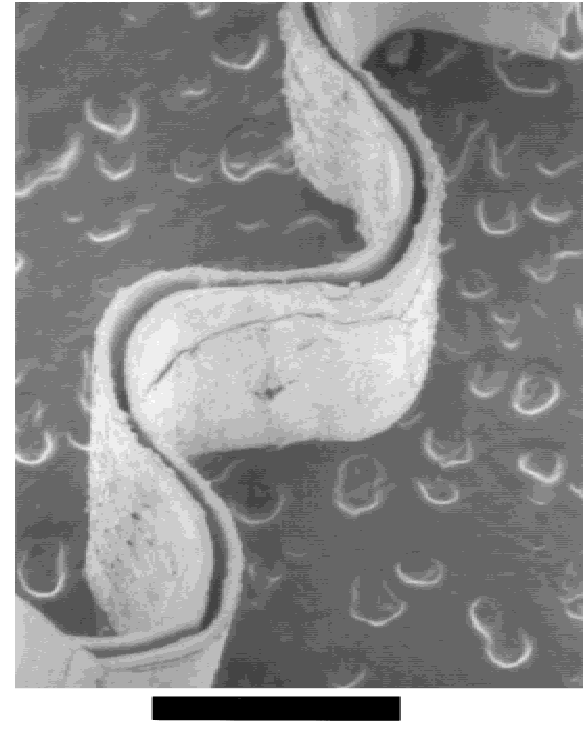

\section{0 microns}

(A)

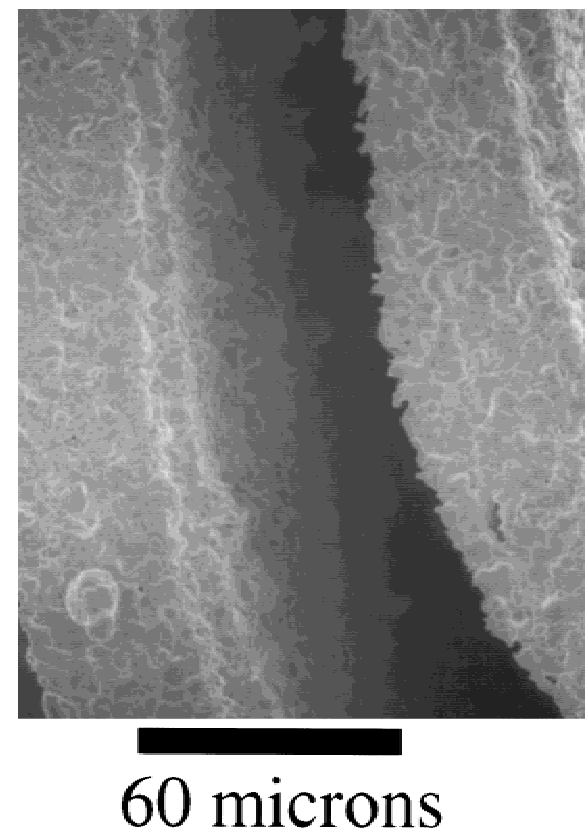

(B)

Fig. 9. Free-standing two-layer $\mathrm{C}$-shape from $\mathrm{PZT}$ after one reduction pass, after sintering at $1250^{\circ} \mathrm{C}$ : (A) low-magnification view showing shape; (B) detail of PZT walls and central space.

The MFCX process is superficially similar to polymer coextrusion, but the latter involves true viscous flow of molten polymers. A much closer analogue ${ }^{8}$ is the art glass process ${ }^{\S \S}$ of millefiori, where a design is assembled from rods of colored glass, although the size reduction occurs by drawing of the glass, rather than extrusion. Co-extrusion and co-drawing of plastic metals may be a closer analogue. An outstanding example of this is the production of $\mathrm{Nb}-\mathrm{Ti}$ superconducting wire, ${ }^{9}$ where quite elaborate arrangements of $\mathrm{Nb}-\mathrm{Ti}$ rods in a

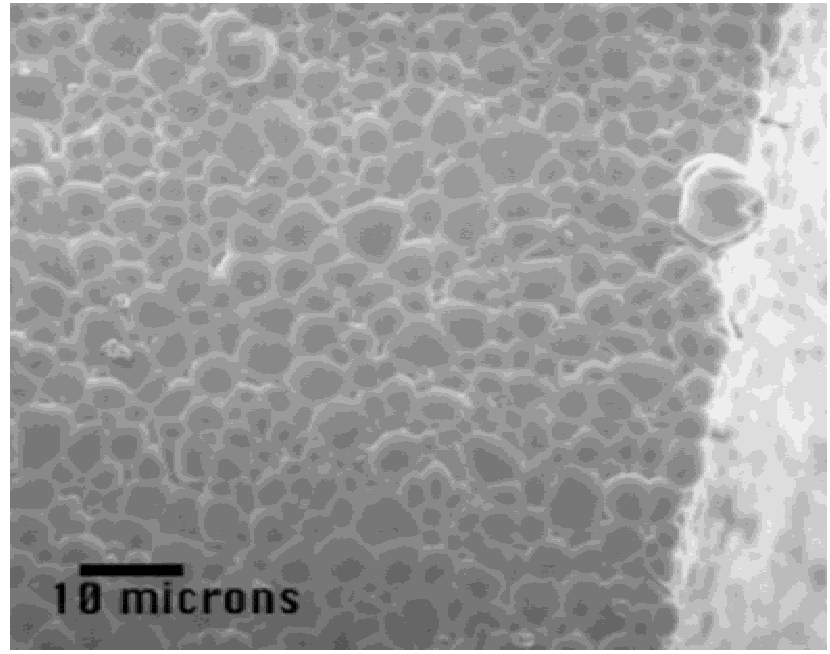

Fig. 10. Edge of a C-shape from PMN-PT after one reduction pass, after sintering at $1100^{\circ} \mathrm{C}$, showing high sintered density.

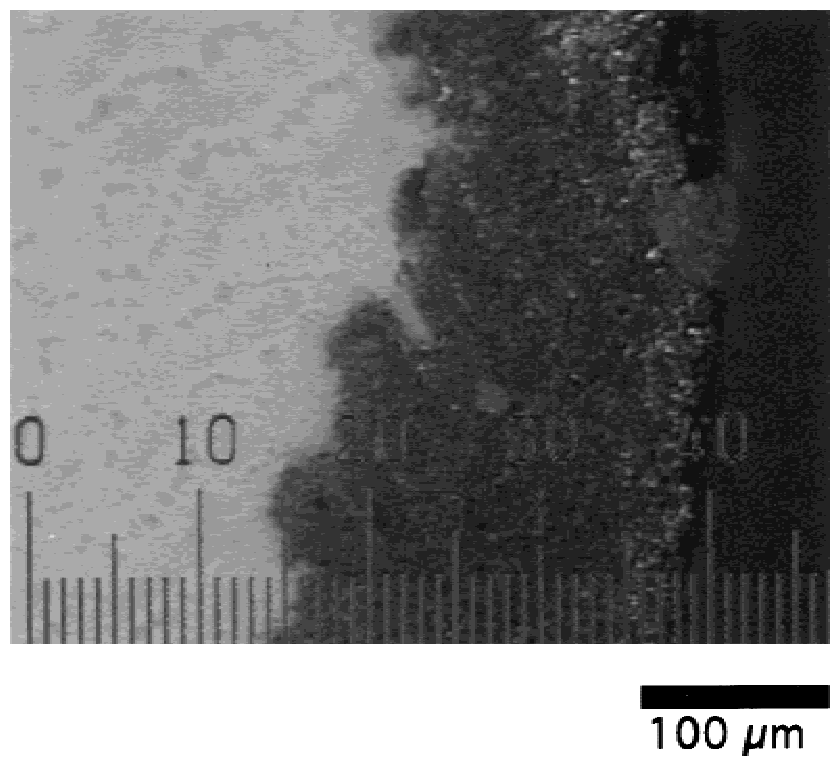

Fig. 11. Instability at the interface between PZT primary material and graphite fugitive material after one reduction at 8:1 ratio.

$\mathrm{Cu}$ matrix are reduced and drawn with great fidelity in kilometer lengths with ultimate reduction ratios on the order of 1000. In this case the metal flows by true plastic deformation, and the two metals must have compatible plastic deformation behavior. Apparently it is possible to obtain significant size reductions with excellent fidelity using either viscous flow or plastic flow. The rheological behavior of our ceramic-polymer compounds have not been fully characterized, but preliminary work $^{10}$ indicates significant plastic behavior under extrusion conditions.

The MFCX process itself only produces a fine-scale green object. Preserving the microfabricated objects during sintering is a challenge. Distortions during sintering are similar to conventional articles. An example is an array of tall fine lines, which tend to slump during sintering. Such shapes, if macroscopic, would be fired with setters to prevent slumping. Discrete setters can be impractical for microfabricated objects, so supports have to be built into the design. For example, a "window frame" can be built around an array of lines to support it during sintering. The relatively straight lines of Fig. 5(B) was from an array with a window frame support, while the slumped 
lines in Fig. 8 were in an unsupported system. Alternately, one could incorporate a second refractory fugitive into the extrudate which could, for example, be dissolved away after sintering. We are currently working on methods to avoid distortion during sintering.

The size of the features produced by MFCX is comparable to those produced using the "lost mold" technique ${ }^{11}$ which involves slip casting into finely patterned plastic molds produced by synchrotron radiation lithography (LIGA). ${ }^{12}$ Feature size from MFCX is also comparable with those achieved by ceramic "micromolding", with photolithographically patterned polyimide ${ }^{13,14}$ molds. These methods are comparable to MFCX, since they produce axisymmetric shapes with very fine features in two dimensions. However, with "lost mold" and " "micromolding"' the fabricated object is very short (about 400 $\mu \mathrm{m}$ thick for the LIGA lost mold method), since these methods essentially create patterned surfaces on a macroscopic substrate. The MFCX objects are macroscopic in the axial direction, as the extrudate is typically $1 \mathrm{~m}$ long. Small threedimensional objects are liberated by machining away the substrate for LIGA lost mold or by slicing the extrudate for MFCX, with the minimum object thickness determined by the machining technique. Thicknesses in the range of several micrometers should be achievable.

Fine-scale structures can also be made by tape casting. For example, Stevenson et al. ${ }^{15}$ reported PZT elements $20 \mu \mathrm{m}$ thick produced by laminating sintered tape cast sheets. Injection molding method have been developed ${ }^{16}$ capable of producing features on the order of $22 \mu \mathrm{m}$.

\section{Conclusions}

Small green ceramic objects with complex axisymmetric shapes can be fabricated by piston extrusion through simple round or square dies. This is done using feedrods in which the primary ceramic plastic compound has the required shape, with the remaining space in the feedrod filled with a second fugitive plastic material. The fugitive material is later removed. The size of the object decreases by the reduction ratio of the die, $R$. Ceramic green objects in the size range of 10-30 $\mu \mathrm{m}$ can be obtained with single reductions at large $R$, or repeated reductions at small $R$.

Carbon black, removed by oxidation, is a useful fugitive for alumina and $\mathrm{PbO}$-containing ferroic oxides. Thermoplastic mixtures of carbon black in ethylene vinyl acetate (EVA) can be co-extruded with mixtures of alumina or lead zirconate titanate (PZT) in EVA. Arrays of $15 \mu \mathrm{m}$ wide green PZT lines were fabricated with a single reduction state at $R=20$. Sin- tered alumina " $M$ '" shapes, $22 \mu \mathrm{m}$ high, were fabricated with four successive reductions at $R=5.5$, for a total size reduction by a factor of 915 .

Acknowledgments: We thank Professor Diann Brei for guidance on applications and Aaron Crumm for helping with the manuscript.

\section{References}

${ }^{1}$ V. F. Janas and A. Safari, "Overview of Fine-Scale Piezoelectric Ceramic/ Polymer Composite Processing," J. Am. Ceram. Soc. 78 [11] 2945-55 (1995).

${ }^{2}$ J. D. Ervin, D. Brei, C. A. Van Hoy, J. R. Mawdsley, and J. W. Halloran, "New Fabrication Process for Active Micro-Sized Metal-Ceramic Devices", pp. 695-702 in Proceedings of the ASME Aerospace Division, AD-Vol. 52. Edited by C. I. Chang, J. Coulter, D. Brei, D. Martinez, W. Ng, and P. P. Friedman. American Society of Mechanical Engineers, New York, 1996.

${ }^{3}$ M. Kahn and M. Chase, "Effects of Heat Treatments on Multilayer Piezoelectric Ceramic-Air Composites," J. Am. Ceram. Soc., 75 [3] 649-56 (1992).

${ }^{4}$ A. Brady, G. Hilmas, and J. W. Halloran, "Forming Textured Ceramics by Multiple Coextrusion"; pp. 321-25 in Ceramic Transactions, Vol. 51, Ceramic Processing Science and Technology. Edited by H. Hausner and G. Messing. American Ceramic Society, Westerville, OH, 1995.

${ }^{5}$ L. L. Blyler, Jr., and J. H. Daane, “An Analysis of Brabender Torque Rheometer Data," Polym. Sci. Eng. [July] 178-81 (1967).

${ }^{6}$ S. Levy and J. F. Carley (Eds.), "Coextrusion and Dual-Extrusion Technology"; Ch. 7 in Plastics Extrusion Technology Handbook, 2nd ed. Industrial Press, New York, 1989.

${ }^{7}$ N. Minagawa and J. C. White, "Co-extrusion of Unfilled and Titania-Filled Polyethylene: Influence of Viscosity and Die Cross Section on Interfacial Stability,'” Polym. Eng. Sci., 15 [Dec.] 825 (1975).

${ }^{8}$ A. C. Revi, Nineteenth Century Glass; pp. 94-100. Schiffler Publishing, Exton, PA, 1967.

${ }^{9}$ E. W. Collings, Applied Superconductivity, Metallurgy, and Physics of Titanium Alloys, Vol. 2. Plenum Press, New York, 1986.

${ }^{10}$ D. Rucker; Ph.D. Thesis in progress. University of Michigan, Ann Arbor, MI.

${ }^{11}$ U. Bast, H. Kaarmann, K. Lubitz, M. Vogt, W. Wersing, and D. Cramer "Composite Ultrasonic Transducer and Method for Manufacturing a Structured Composite Therefrom of Piezoelectric Ceramics,' U.S. Pat. No. 5164920 , 1992.

${ }^{12}$ E. W. Becker, W. Erhfeld, P. Hagmann, A. Maner, and D. Muchmeyer, "Fabrication of Microstructures with High Aspect Ratios and Great Structural Heights by Synchrotron Radiation Lithography, Gavanoforming, and Plastic Molding (LIGA Process),"' Microelectron. Eng., 4, 35-56 (1986).

${ }^{13}$ J. A. Bride, S. Baskaran, N. Taylor, J. W. Halloran, W. H. Juan, S. W. Pang, and M. O'Donnell, 'Photolithographic Micromolding of Ceramics Using Plasma Etched Polyimide Patterns," Appl. Phys. Lett., 63 [24] 3379-81 (1993).

${ }^{14}$ M. L. Griffith, A. Barda, N. Taylor, J. W. Halloran, W. H. Juan, and S. W. Pang, "Micromolding of Ceramics using Photolithographic Polyimide Patterns"; pp. 321-25 in Ceramic Transactions, Vol. 51, Ceramic Processing Science and Technology. Edited by H. Hausner and G. Messing. American Ceramic Society, Westerville, OH, 1995.

${ }^{15} \mathrm{~J}$. W. Stevenson, M. R. Reidmeyer, and W. Huebner, "Fabrication and Characterization of PZT/Thermoplastic Polymer Composites for High Frequency Phased Linear Arrays," J. Am. Ceram. Soc., 77 [9] 2481-84 (1994).

${ }^{16}$ P. G. Pazol, L. J. Bowen, R. L. Gentilman, H. T. Phan, W. J. Serwatk, C. G. Oakley, and D. R. Dietz, "Ultrafine Piezoelectric Composite Materials for High Frequency Ultrasonic Transducers"; presented at the 1995 IEEE Ultrasonics Symposium, Seattle, WA, November 1995. 